\title{
Universiteit
}

Leiden

The Netherlands

\section{Synthesis and antiproliferative activity of hindered, chiral 1,2- diaminodiamantane platinum(II) complexes}

Bakhonsky, V.V.; Pashenko, A.A.; Becker, J.; Hausmann, H.; Groot, H.J.M. de; Overkleeft, H.S.; ... ; Schreiner, P.R.

\section{Citation}

Bakhonsky, V. V., Pashenko, A. A., Becker, J., Hausmann, H., Groot, H. J. M. de, Overkleeft, H. S., ... Schreiner, P. R. (2020). Synthesis and antiproliferative activity of hindered, chiral 1,2-diaminodiamantane platinum(II) complexes. Dalton Transactions, 49(40), 14009-14016. doi:10.1039/d0dt02391d

Version: Publisher's Version

License: $\quad$ Licensed under Article 25fa Copyright Act/Law (Amendment Taverne)

Downloaded from: https://hdl.handle.net/1887/3201132

Note: To cite this publication please use the final published version (if applicable). 
(A) Check for updates

Cite this: Dalton Trans., 2020, 49, 14009

Received 6th July 2020,

Accepted 28th August 2020

DOI: $10.1039 / \mathrm{d} 0 \mathrm{dt} 02391 \mathrm{~d}$

rsc.li/dalton

\title{
Synthesis and antiproliferative activity of hindered, chiral 1,2-diaminodiamantane platinum(॥) complexes $\uparrow$
}

\author{
Vladyslav V. Bakhonsky, ${ }^{a, b}$ Aleksander A. Pashenko, ${ }^{\text {b,c }}$ Jonathan Becker, ${ }^{d}$ \\ Heike Hausmann, ${ }^{a}$ Huub J. M. De Groot, (D) ${ }^{c}$ Herman S. Overkleeft, (D) ${ }^{c}$ \\ Andrey A. Fokin*a,b and Peter R. Schreiner (D)*a
}

\begin{abstract}
Platinum-based antineoplastic agents play a major role in the treatment of numerous types of cancer. A new bulky, lipophilic, and chiral ligand based on 1,2-diaminodiamantane in both of its enantiomeric forms was employed for the preparation of new platinum(॥) complexes with chloride and oxalate ligands. The dichloride complexes have a higher solubility and were evaluated as anti-proliferation agents for human ovarian cancer cell lines A2780 and cisplatin-resistant A2780cis. Its R,R-enantiomer showed increased efficacy compared to cisplatin for both cancer cell lines. A chromatographic approach was used to estimate the solvent partition coefficient of the dichloride complex. The binding of diamondoid-based platinum complexes to nucleotides was tested for both enantiomers with guanosine monophosphate (GMP) and deoxyguanosine monophosphate (dGMP) and occurs at a similar or faster rate for both isomers compared to cisplatin despite greatly increased steric demand. These findings highlight the potential in 1,2diaminodiamantane as a viable pharmacophore.
\end{abstract}

\section{Introduction}

Cisplatin [cis-dichlorodiamineplatinum(II)] (Fig. 1), first tested in 1968, was approved worldwide in 1978 after being accidentally discovered to have antiproliferative activity by Rosenberg during electrochemical treatment of living cells using platinum electrodes. ${ }^{1}$ This discovery dramatically changed cancer treatment regimens with platinum-based drugs being incorporated as effective agents by themselves or in combination with other antineoplastic medication in $>50 \%$ of formulations for a wide variety of cancer cell types. Cisplatin is still the preferred drug for ovarian and testicular cancer providing $90 \%$ cure rate for the latter. ${ }^{2,3}$ There is converging evidence that the mechanism of action of cisplatin and its analogues with the

\footnotetext{
${ }^{a}$ Institute of Organic Chemistry, Justus Liebig University, Heinrich-Buff-Ring 17, 35392 Giessen, Germany and Center for Materials Research (LaMa), Justus Liebig University, Heinrich-Buff-Ring 16, 35392 Giessen, Germany.

E-mail: prs@uni-giessen.de

${ }^{b}$ Department of Organic Chemistry, Igor Sikorsky Kiev Polytechnic Institute, Pobedy Ave.37, 03056 Kiev, Ukraine.E-mail: aaf@xtf.kpi.ua

${ }^{c}$ Leiden Institute of Chemistry, Leiden University, Einsteinweg 55, 2300RA Leiden, The Netherlands

${ }^{d}$ Institute of Inorganic and Analytical Chemistry, Justus-Liebig-Universität, HeinrichBuff-Ring 17, 35392 Giessen, Germany

$\dagger$ Electronic supplementary information (ESI) available: NMR spectra and crystallographic data. CCDC 1956841 and 1956840. For ESI and crystallographic data in CIF or other electronic format see DOI: 10.1039/d0dt02391d
}

general formula $\left[\mathrm{PtX}_{2}\left(\mathrm{RNH}_{2}\right)_{2}\right]$ involves hydrolysis of the diamine complexes inside cancer cells producing the charged $\left[\mathrm{Pt}\left(\mathrm{NH}_{3}\right)_{2}\left(\mathrm{H}_{2} \mathrm{O}\right)_{2}\right]^{2+}$ complex that quickly loses water and forms inter- and intrastrand DNA cross-links blocking repair mechanisms. The majority of cross-links are guanosine-guanosine $\mathrm{d}(\mathrm{GpG})$ and, to lesser extent, adenosine-guanosine $\mathrm{d}(\mathrm{ApG})$ intrastrand cross-links formed by platinum diamine complexes and adjacent purine bases. ${ }^{4}$ The resulting platinum adducts interfere with DNA replication triggering cell apoptosis. ${ }^{5}$ Despite beneficial cytotoxicity used to target cancer cells, cisplatin treatment has drawbacks such as dose-limiting peripheral neurotoxicity, gastrointestinal toxicity, ototoxicity, hematological toxicity and severe nephrotoxicity, being potentially lethal for patients without modern hydration techniques. ${ }^{6-11}$ Furthermore, it quickly became evident that numerous cancer cell types have intrinsic or acquired resistance towards cisplatin. ${ }^{12-14}$ In an attempt to overcome the limitations of cis-

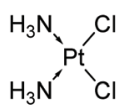

cisplatin

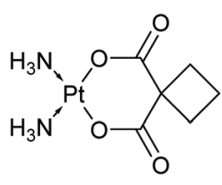

carboplatin<smiles>O=C1O[P]2(N[C@H]3CCCC[C@H]3N2)OC1=O</smiles>

oxaliplatin
Fig. 1 Chemical structures of platinum anticancer drugs approved worldwide. 
platin, carboplatin was developed. This second-generation platinum agent has chlorine ligands substituted by a bidentate cyclobutanedicarboxylate moiety. Carboplatin has a greatly reduced toxicity profile, allowing adjustment of the active dosage to individual patients, although it has decreased anticancer activity requiring 20-40 fold increase in concentration to achieve the same effect as for cisplatin. ${ }^{3,11}$

Despite being actively used in treatment of ovarian cancer, the dose-limiting myelosuppression (thrombocytopenia and to lesser extent neutropenia and anemia) still remains a significant drawback. ${ }^{3,11,15}$ Carboplatin has the same mechanism of action inside the cell as cisplatin. Consequently, numerous cancer cell types, known to acquire cisplatin resistance, exhibit cross-resistance to carboplatin as well. ${ }^{11,16,17}$

The third-generation platinum drugs were developed to further counter cisplatin resistance. Oxaliplatin, the most recent worldwide-approved anticancer drug based on platinum, ${ }^{18,19}$ displays a bidentate oxalate moiety instead of the two chloride anions in cisplatin, as well as amino ligands derived from $(1 R, 2 R)-1,2$-diaminocyclohexane [(R,R)-DACH]. The larger and more lipophilic 1,2-diaminocyclohexane $[1,2-$ $\mathrm{DACH}]$ significantly changes the cytotoxicity profile and provides very limited cross-resistance to cisplatin, which is linked to the steric properties of the DACH adduct that hinders the DNA repair mechanism within tumor cells. ${ }^{18,20}$ Differences in activity manifest themselves in the particular effectiveness of oxaliplatin in the treatment of colorectal cancer, which is unresponsive to cisplatin and carboplatin. ${ }^{19,20}$

New generations of platinum-based anticancer drugs with diverse cytotoxicity profiles require different diamine carrier ligands that are responsible for interactions with DNA inside cancer cells. The lipophilicity of these ligands increases absorption and accumulation of the platinum complex within the cell while decreasing the requirement for renal excretion, thus reducing toxic side effects. ${ }^{21,22}$ trans-1,2Diaminocyclohexane is the most popular diamine pharmacophore, although other hydrocarbon backbones receive increasing attention. For instance, kiteplatin $\left[\mathrm{PtCl}_{2}(\right.$ cis-1,4-DACH $\left.)\right]$, first synthesized in 1994, incorporates a 1,2-DACH isomer; it lacks cross-resistance with already approved anticancer drugs. ${ }^{23,24}$ The more bulky and lipophilic 2,3-diaminobicyclo [2.2.1] heptane, 2,3-diaminobicyclo[2.2.1]heptane, camphor1,2-diamine, and their analogues (Fig. 2) were recently utilized as carrier ligands, some of which exhibited promising antiproliferative properties when paired with appropriate leaving ligands in platinum complexes. ${ }^{25-31}$

We suggest 1,2-diaminodiamantane as a viable alternative to known lipophilic diamine pharmacophores. Diamondoids among other polycyclic hydrocarbons have already displayed potential as promising scaffolds for medicinal chemistry. ${ }^{32,33}$ Our recent work on diamantane functionalization ${ }^{34}$ provides direct access to previously unknown 1,2-disubstituted diamondoids and 1,2-diaminodiamantane in particular. The bulky diamantane backbone provides high lipophilicity in a compact and extraordinarily stable lattice. Being conformationally rigid, 1,2-diaminodiamantane may present signifi-

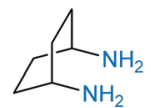

cis-1,4-DACH
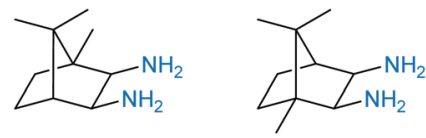

cis-1,2-camphordiamine ligands
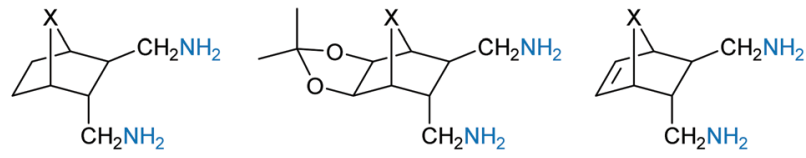

$\mathrm{X}=\mathrm{O}, \mathrm{CH}_{2}, \mathrm{CH}_{2} \mathrm{CH}_{2}$

1,2-bis(aminomethyl)bicyclic ligands

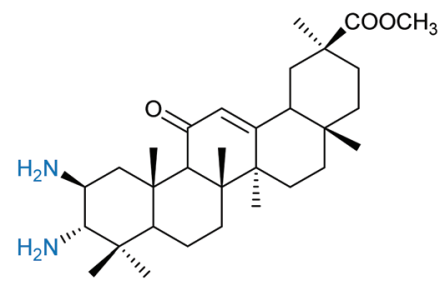

polycyclic terpenoidal diamine

trans-bicyclo[2.2.2]octane-7,8-diamine
Fig. 2 Bulky diamine ligands known to be tested in various platinum complexes for antiproliferative activity.

cant steric and kinetic hindrance to the DNA repair mechanism, which may further increase the efficacy of its platinumDNA adduct. The two available stereoisomers of 1,2-diaminodiamantane are the $R, R$ and $S, S$ enantiomers that introduce chirality into their corresponding platinum complexes, which is known to play a major role in platinum drug efficacy. ${ }^{35}$

In this study we synthesized two diamantane based platinum complexes in both of their enantiopure forms (Fig. 3) and tested them in cancer cell assays. The $(R, R)-\mathbf{2}$ and $(S, S)-\mathbf{2}$ complexes were found to have extremely low solubility and were not used in activity studies. Although these complexes (termed diaplatins) generally exhibit decreased solubility compared to cisplatin, we were able to grow a crystal of $(S, S)-\mathbf{1}$ and compare its geometry to the structures of 1,2-diaminocyclohexanedichloroplatinum(II) [ $\left.\mathrm{PtCl}_{2}(1,2-\mathrm{DACH})\right]$ and cisplatin. Using reverse phase high pressure liquid chromatography (RP-HPLC), we were able to estimate the lipophilicity of the

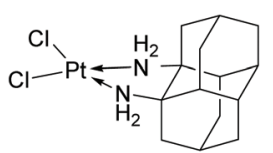

$(R, R)-1$

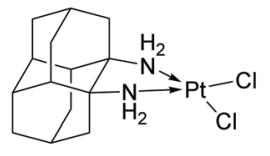

$(S, S)-1$

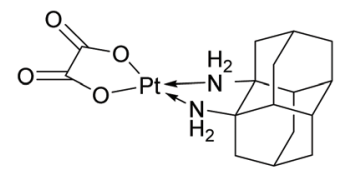

$(R, R)-2$

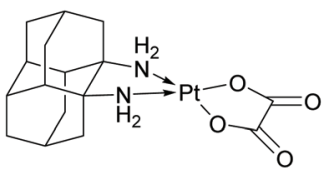

$(S, S)-2$
Fig. 3 Investigated diamondoid-based platinum complexes. 
dichloride complex using a range of reference compounds with known partition coefficients. The diaplatin enantiomers were tested for their cytotoxicity via a cell viability assay conducted on the human ovarian cancer cell line A2780 and its cisplatin-resistant variant A2780cis. $(R, R)$-1 displays higher cytotoxicity than cisplatin for both cell lines, while $(S, S)-\mathbf{1}$ shows lower or similar activity as compared to cisplatin, which shows similar to the known reactivity of oxaliplatin comprising $(R, R)$-DACH and its $S, S$-diamine-based counterpart. ${ }^{36-38} \mathrm{We}$ evaluated GMP and dGMP binding rates for both $(R, R)-1$ and $(S, S)$-1 complexes using NMR spectroscopy. Despite the increased steric demand, charged diamantanediaminoplatinum complexes have binding rates comparable to cisplatin. $(R, R)-\mathbf{1}$ shows increased activity and cytotoxicity compared to cisplatin, thereby benefiting from its bulky backbone with inherent chirality.

\section{Experimental}

\section{Preparation of platinum complexes}

Materials and methods. Chemicals, solvents, and reagents for biological assays were of analytical or equivalent grade and were used as received. Melting points were measured in closed capillaries on Krüss KSP1N melting point meter. NMR spectra were recorded on Bruker DPX-300 $300 \mathrm{MHz}$ spectrometer (300 MHz for ${ }^{1} \mathrm{H}$, $75 \mathrm{MHz}$ for ${ }^{13} \mathrm{C}$, $64 \mathrm{MHz}$ for ${ }^{195} \mathrm{Pt}$ ) using DMF-d7 as a solvent. Chemical shifts are given in parts per million (ppm). High-resolution mass spectra were recorded on Bruker Daltonics micrOTOF mass spectrometer using ESI (electrospray ionization). Elemental analysis was performed on Thermo FlashEA 1112 Series CHN elemental analyzer. IR spectra were recorded on Bruker Optics VERTEX70/Platinum ATR. Purity was confirmed via HPLC using Dionex P680 pump, Rheodyne 8125 injector and Shodex RI-101 ELSD. 1,2Diaminodiamantane was synthesized and separated on enantiomers according to the published procedure. ${ }^{34}$

cis-[1,2-Diaminodiamantane]dichlorideplatinum(II) (1). 1,2Diaminodiamantane $(0.1 \mathrm{~g}, 0.46 \mathrm{mmol})$ was added to a solution of $\mathrm{K}_{2} \mathrm{PtCl}_{4}(0.19 \mathrm{~g}, 0.46 \mathrm{mmol})$ in water $(2 \mathrm{~mL})$ and the resulting mixture was stirred for $24 \mathrm{~h}$ at $\mathrm{rt}$. The yellow precipitate formed and was filtered, washed with acetone, recrystallized from a water/DMF mixture, and dried under reduced pressure at $40{ }^{\circ} \mathrm{C}$ for $24 \mathrm{~h}$. We obtained yellow crystals of $1(0.085 \mathrm{~g})$ in $37 \%$ yield. Mp $314{ }^{\circ} \mathrm{C}$ (dec.). ${ }^{1} \mathrm{H}$ NMR (300 MHz, DMF-d7): $\delta$ 5.18-4.84 (m, 4H, $\mathrm{NH}_{2}$ ), 2.78-2.66 (m, 2H), 2.65-2.51 (m, 2H), 2.04-1.93 (m, 4H), 1.77-1.66 (m, 4H), 1.66-1.55 (m, 4H), 1.47-1.35 (m, 2H). ${ }^{13} \mathrm{C}$ NMR (75 MHz, DMF-d7): $\delta 64.5$ (C), $43.5(\mathrm{CH}), 40.2(\mathrm{CH}), 38.2\left(\mathrm{CH}_{2}\right), 38.0\left(\mathrm{CH}_{2}\right), 31.7\left(\mathrm{CH}_{2}\right), 28.8$ (CH). ${ }^{195} \mathrm{Pt}$ (64 MHz, DMF-d7): $\delta$ 2251. HRMS (ESI): calcd for $\mathrm{C}_{14} \mathrm{H}_{22} \mathrm{~N}_{2} \mathrm{Cl}_{2} \mathrm{NaPt}^{+}[\mathrm{M}+\mathrm{Na}]^{+}=506.0700$ found 506.0702. HPLC (Chiralpak IB, 35\% methanol, 65\% tert-butyl methyl ether, $\left.1.0 \mathrm{~mL} \mathrm{~min}^{-1}\right)$ : $(R, R)-1$ ret. time $6.04 \mathrm{~min}>99 \%$ purity, $>99 \%$ ee; $(S, S)$-1 ret. time $5.76 \mathrm{~min}>99 \%$ purity, $>99 \%$ ee.

cis-[1,2-Diaminodiamantane]oxalatoplatinum(II) (2). A solution of 1,2-diaminodiamantane $(0.1 \mathrm{~g}, 0.46 \mathrm{mmol})$ in isopro- panol $(5 \mathrm{~mL})$ was added to a solution of $\mathrm{K}_{2}\left[\mathrm{Pt}(\mathrm{ox})_{2}\right] \cdot 2 \mathrm{H}_{2} \mathrm{O}$ $(0.187 \mathrm{~g}, 0.41 \mathrm{mmol})$ in water $(5 \mathrm{~mL})$ preheated to $50{ }^{\circ} \mathrm{C}$. The resulting mixture was stirred at $70{ }^{\circ} \mathrm{C}$ for $72 \mathrm{~h}$ in the dark. The precipitated off-white powder was filtered, washed with water and acetone, and dried under reduced pressure. We obtained off-white crystals of 2 (0.06 g) in 29\% yield. Mp $267{ }^{\circ} \mathrm{C}$ (dec.). IR $\nu_{\max } / \mathrm{cm}^{-1}: 2913 \mathrm{br}, 1694 \mathrm{~s}, 1667 \mathrm{~s}, 1598 \mathrm{w}, 1357 \mathrm{~s}, 818 \mathrm{~s}, 561 \mathrm{w}$, 459 w. Due to the insolubility of the obtained solid material, no further purification and analysis could be completed. Therefore, the complex was not used in further investigations.

\section{Crystallographic structure measurements}

Crystallographic data for 1,2-diaminodiamantane dihydrochloride and $(S, S)$-1 were collected at $100 \mathrm{~K}$ using $\varphi$ - and $\omega$-scans on a BRUKER D8 Venture system equipped with dual $\mathrm{I} \mu \mathrm{S}$ microfocus sources, a PHOTON100 detector and an OXFORD CRYOSYSTEMS 700 low temperature system. Mo-K $\alpha$ radiation with a wavelength of $0.71073 \AA$ and a collimating Quazar multilayer mirror were used. Semi-empirical absorption corrections from equivalents for 1,2-diaminodiamantane dihydrochloride and numerical absorption corrections for $(S, S)$-1 were applied using SADABS-2016/2. ${ }^{39}$ The space groups were determined by systematic absences using XPREP and the structures were solved by direct methods using SHELXT. ${ }^{40}$ Refinement for all structures was performed against $F^{2}$ on all data by full-matrix least squares using SHELXL. ${ }^{41}$ All nonhydrogen atoms were refined anisotropically and $\mathrm{C}-\mathrm{H}$ hydrogen atoms were positioned at geometrically calculated positions and refined using a riding model. $\mathrm{O}-\mathrm{H}$ and $\mathrm{N}-\mathrm{H}$ hydrogen atoms were located in the Fourier difference map and set to ideal distances. The isotropic displacement parameters of all hydrogen atoms were fixed to $1.2 \times$ or $1.5 \times\left(\mathrm{CH}_{3}\right.$ and $\mathrm{OH}$ hydrogens) the $U_{\text {eq }}$ value of the atoms they are linked to.

Deposition Numbers 1956841, $1956840 \dagger$ contain the supplementary crystallographic data for this paper.

\section{Lipophilicity measurements}

The lipophilicity of complex 1 was studied with its $R, R$-enantiomer using RP-HPLC. Measurements were done on with a setup comprising a Dionex LPG-3400A pump, VWD-3100 detector, ASI-100 sampler, and a Degasys DG-1310 degasser. The reverse-phase column was a Knauer Eurospher IIC18 $4 \times$ $250 \mathrm{~mm}$ for all experiments. Various mixtures of acetonitrile in water were used as mobile phases. To establish the dead time of the column, potassium iodide was used as a dead volume marker. A series of compounds with known $\log P$ values were injected in the same reverse-phase column to establish a reference curve. The flow rate was kept constant at $1 \mathrm{~mL} \mathrm{~min}^{-1}$ for all experiments. A UV detector was used at $210 \mathrm{~nm}$. A series of retention times, measured for each compound, was used to calculate capacity factors $k$ according to eqn (1):

$$
k=\frac{t_{\mathrm{R}}-t_{0}}{t_{0}}
$$

where $t_{\mathrm{R}}$ is the retention time and $t_{0}$ the dead time of the column. The capacity factor $k$ was determined at least three 
times for each compound using different combinations of acetonitrile and water. The results were analyzed using a linear regression as a relationship between $\log k$ and concentration of acetonitrile in the mobile phase $(\phi)$. This allowed to extrapolate the $\log k_{\mathrm{w}}$ values corresponding to capacity factor of the compound in $100 \%$ water. The calculated $\log k_{\mathrm{w}}$ values for the reference compounds were plotted against their experimental $\log P$ values and analysed using a linear regression to establish the relationship curve. The partition coefficient for complex 1 was then estimated with a $95 \%$ confidence interval.

\section{Cell viability assay}

The human ovarian cancer cell line A2780 (ECACC 93112519) and its cisplatin-resistant variant A2780cis (ECACC 93112517) were grown as a monolayer at $37^{\circ} \mathrm{C}$ in an atmosphere containing $5 \% \mathrm{CO}_{2}$ in RPMI medium (Gibco BRLTM, Invitrogen Corporation, Netherlands) with $10 \%$ fetal bovine serum (Hyclone, Perbio Science, Netherlands), benzylpenicillin sodium salt (Penicillin G sodium salt, 100 units per $\mathrm{mL}$; Dufecha, Biochemie BV, Netherlands), streptomycin (100 $\mu \mathrm{g}$ $\mathrm{mL}^{-1}$; Dufecha, Biochemie BV, Netherlands), and $2 \mathrm{mM}$ Glutamax $\times 100$ (Gibco BRLTM, Netherlands). The cells were seeded at 20000 cells $\mathrm{cm}^{-2}$ in 96 -well plates after transferring them with a micropipette from the source culture after trypsinization. Diaplatins and cisplatin as the standard were introduced as solutions in DMF. The concentration in the first well was $270 \mu \mathrm{M}$ and 1\% DMF for $(R, R)-\mathbf{1},(S, S)-\mathbf{1}$, cisplatin and $1 \%$ DMF for the control experiment. In every following well, the concentration of the platinum complexes and DMF was progressively halved. Cells were incubated for $72 \mathrm{~h}$ at $37^{\circ} \mathrm{C}$ in an atmosphere containing $5 \% \mathrm{CO}_{2}$. The cell viability was then analyzed by addition of resazurin sodium salt (Alamar Blue) to cell cultures followed by incubation for $6 \mathrm{~h}$ and fluorescence assay of the thus produced resorufin. The evaluation of cell survival was performed with an Epoch Microplate Spectrophotometer (BioTek Instruments) to measure absorbance at $570 \mathrm{~nm}$. All conducted cytotoxicity experiments for $(R, R)-\mathbf{1},(S, S)-\mathbf{1}$, cisplatin, and the control solution containing DMF were run eight times in parallel for each cell line and were done in triplicate. The cytotoxicities of the platinum complexes were calculated using non-linear regression analysis of dose-response data and expressed as half maximal inhibitory concentrations $\left(\mathrm{IC}_{50}\right)$. Statistical analysis was performed with GraphPad Prism 7.

\section{Nucleotide binding experiments}

The rates of $(R, R)-\mathbf{1},(S, S) \mathbf{- 1}$, and cisplatin binding with guanosine monophosphate (GMP) and deoxyguanosine monophosphate (dGMP) nucleotides were studied using ${ }^{1} \mathrm{H}$ NMR spectroscopy. A platinum complex solution in DMF-d7 $(0.27 \mathrm{~mL}$, $6.9 \mathrm{mM}$ ) reacted with GMP or dGMP in a molar ratio $1: 3.5$ introduced with a $\mathrm{NaClO}_{4}$ solution in $\mathrm{D}_{2} \mathrm{O}(0.33 \mathrm{~mL}, 100 \mathrm{mM})$. The reaction mixture was immediately transferred into an NMR tube and ${ }^{1} \mathrm{H}$ NMR data were collected every hour for $66 \mathrm{~h}$ at $37{ }^{\circ} \mathrm{C}$. The $\mathrm{pH}$ was measured immediately after the reaction mixture was prepared and at the end of the reaction at rt.

\section{Results and discussion}

Platinum complexes synthesis and structure analysis

For the synthesis of diaplatin complexes $\mathbf{1}$ and $\mathbf{2}$ we decided to utilize silver-free methods to prevent microscopic concentrations of silver from contaminating the samples. Silver is a potent cytotoxic agent and multiple crystallizations in addition to other purification procedures are required to remove its traces and avoid its influence on the cytotoxicity profile of platinum samples.

To prepare $(R, R)-\mathbf{1}$ and $(S, S)-\mathbf{1}$, the pure 1,2-diaminodiamantane enantiomers were reacted with $\mathrm{K}_{2} \mathrm{PtCl}_{4}$. The reaction mixture was stirred for three days protected from light and followed by filtration. The $(R, R)-2$ and $(S, S)-2$ oxalate complexes, $\mathrm{K}_{2}\left[\mathrm{Pt}(\mathrm{Ox})_{2}\right]$ prepared from $\mathrm{K}_{2} \mathrm{PtCl}_{4}$ and potassium oxalate, were reacted with the 1,2-diaminodiamantane enantiomers in a similar fashion. This procedure gives diamantane-based platinum complexes in good yields (Scheme 1).

The oxalate complexes are off-white and the dichloride complexes are yellow, which is common for this class of platinum structures, and they have notably decreased solubility compared to cisplatin. Furthermore, $(R, R)-2$ and $(S, S)-2$ are insoluble in most common solvents including $N, N$-dimethylformamide (DMF), known to dissolve platinum complexes. However, 1 displays good solubility in DMF and is somewhat soluble in methanol. It can be stored as a solution in these solvents for months in a closed vial without significant decomposition. Solutions in DMSO cause a precipitate to form and show significant decomposition (NMR), which is known for platinum complexes. ${ }^{42}$ After initial tests $(R, R)-2$ and $(S, S)-2$ were discarded because they were not soluble enough to reach active concentrations for cytotoxicity assays.

Crystallization of the 1,2-diaminodiamantane dihydrochloride from methanol gave crystals suitable for X-ray single diffraction analysis. The solved structure (Fig. 4A) shows the absolute configuration of $(S, S)$, determined via anomalous dispersion, with a high degree of purity reflected in the Flack parameter $^{43}$ being close to zero (Table S1 $\dagger$ ).

Using a two-phase diffusion technique with DMF as the primary solvent and diethyl ether as the second phase, we were able to grow a crystal of $(S, S)-\mathbf{1}$ and obtain its crystal structure

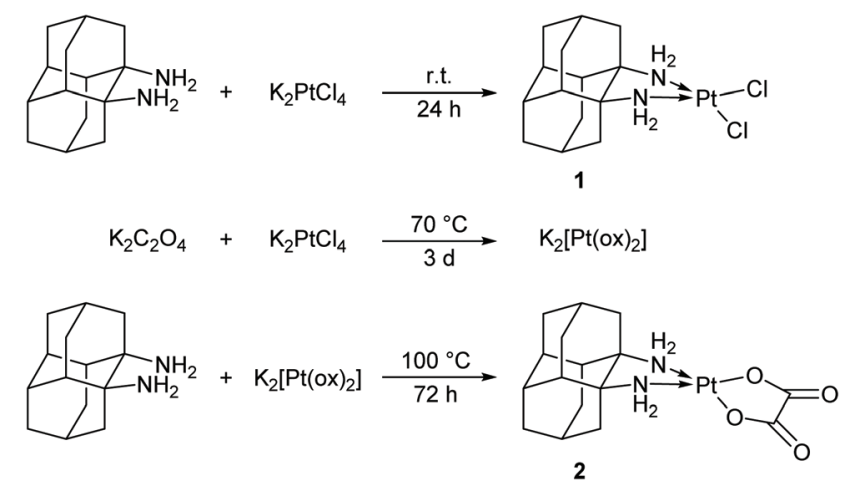

Scheme 1 Preparation of the diaplatin complexes 1 and 2. 


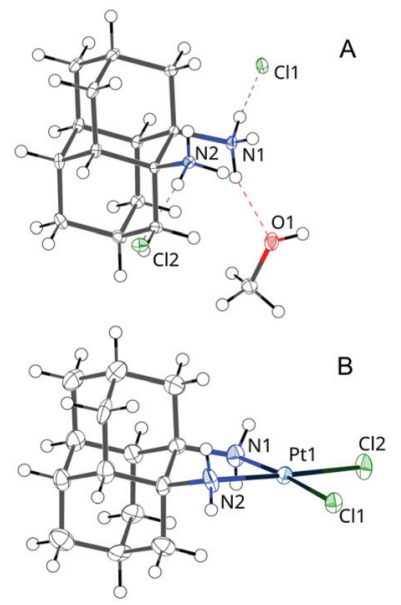

Fig. 4 The molecular structures obtained by crystal structure analysis of $(S, S)$-1,2-diaminodiamantane dihydrochloride in a cell with a methanol molecule (A) and of $(S, S)-1$ (B). Ellipsoids drawn at $50 \%$ probability.

Table 1 Diaplatin 1, $\quad\left[\mathrm{PtCl}_{2}(1,2-\mathrm{DACH})\right]$, and cisplatin geometry comparisons $^{a}$

\begin{tabular}{llll}
\hline & Diaplatin 1 & {$\left[\mathrm{PtCl}_{2}(1,2-\mathrm{DACH})\right]^{b}$} & Cisplatin $^{c}$ \\
\hline $\mathrm{Pt}-\mathrm{N}$ & $2.027(5)$ & $2.036(6)$ & $2.048(3)$ \\
$\mathrm{Pt}-\mathrm{Cl}$ & $2.304(1)$ & $2.321(2)$ & $2.321(8)$ \\
$\mathrm{C}-\mathrm{N}$ & $1.511(8)$ & $1.497(9)$ & - \\
$\mathrm{C}(1)-\mathrm{C}(2)$ & $1.530(7)$ & $1.4965(85)$ & - \\
$\angle$ (NPtCl) & $91.49(14)$ & $90.83(20)$ & $88.87(9)$ \\
$\angle$ (ClPtCl) & $92.83(5)$ & $94.73(7)$ & $91.65(3)$ \\
$\angle$ (NPtN) & $84.25(19)$ & $83.65(20)$ & $90.62(12)$
\end{tabular}

${ }^{a}$ Bonds lengths in $\AA$, angles in deg., SD in parentheses. ${ }^{b}$ Ref. 44. ${ }^{c}$ Ref.45.

(Fig. 4B). The structure for the $(S, S)-\mathbf{1}$ crystal was solved in the hexagonal space group $P 622$ and the absolute structure could be determined again with a Flack parameter close to zero (Table S7 $\dagger)$. We compared the crystal structure of $\mathbf{1},\left[\operatorname{PtCl}_{2}(1,2-\right.$ DACH)], and cisplatin (Table 1). Overall, the geometry of 1 is very close to the geometries of $\left[\mathrm{PtCl}_{2}(1,2-\mathrm{DACH})\right]$ and cisplatin with a few differences imposed by the rigid diamondoid moiety.

\section{Lipophilicity measurements}

The octanol-water partition coefficient $(P)$ is a widely used value for estimating membrane permeability in drug discovery. One of the most commonly employed methods is RP-HPLC ${ }^{46}$ based on measuring the capacity factor $\left(\log k_{\mathrm{w}}\right)$ values, which directly correlate with experimental $\log P$ values. ${ }^{47}$ Furthermore, RP-HPLC is known for producing reliable results for platinum complexes. ${ }^{48,49}$ We chose to assess the $(R, R)-\mathbf{1}$ and a range of organic compounds with known $\log P$ values ${ }^{50,51}$ for reference. Retention times were measured at different isocratic concentrations of acetonitrile in water as mobile phase and using eqn (1) were converted to capacity factors $\log k$ for every measurement (Fig. 5A). Capacity factors
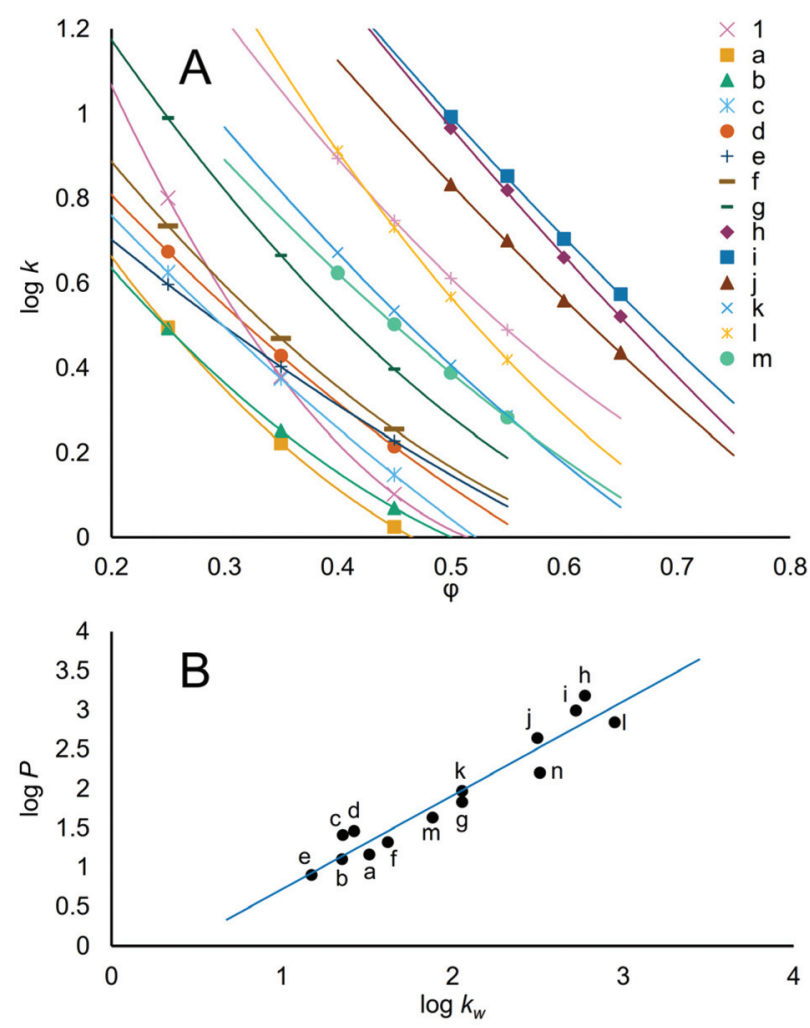

Fig. 5 The capacity factor $(\log k)$ dependence on acetonitrile concentration $(\phi)$ in moving phase (A) and correlation of experimental $\log P$ values of reference compounds with their measured capacity factor $\left(\log k_{\mathrm{w}}\right)$ in $100 \%$ water (B): (1), $(R, R)-1$; (a), acetanilide; (b), benzylic alcohol; (c), phenylacetic acid; (d), phenol; (e), aniline; (f), guaiacol; (g), $p$-cresol; (h), benzophenone; (i), bromobenzene; (j), ethyl benzoate; (k), p-chloroaniline; (l), 1-naphthol; (m), acetophenone; (n), methyl benzoate.

in $100 \%$ water $\left(\log k_{\mathrm{w}}\right)$ were extrapolated from these values via linear regression analysis. The experimental $\log P$ values of the reference compounds were used to establish relationship curves between partition coefficients and capacity factors (Fig. 5B) using linear regression analysis. $\log P \pm 95 \%$ CI of $(R, R)-1$ was then found to be $2.50 \pm 0.16$, which is more than four logarithmic units higher than cisplatin ${ }^{52-55}$ reported in the range from -2.13 to -2.45 . Hence, the compact diamondoid ligand offers an alternative to long alkyl chains with different pharmacological activity and significantly increased lipohilicity.

\section{Cell viability assay}

The platinum complexes $(R, R)-\mathbf{1},(S, S)-\mathbf{1}$ were tested against the human ovarian cancer cell line A2780 and its cisplatin-resistant variant $\mathbf{A} 2780$ cis. Compounds $(R, R)-\mathbf{1},(S, S)-\mathbf{1}$, and cisplatin were introduced to cell cultures in ten different concentrations and incubated for $72 \mathrm{~h}$ at $37{ }^{\circ} \mathrm{C}$. We used standard procedures for adding a fluorescent dye to cell wells and, using spectrophotometry, we collected dose-response data (Fig. 6) to determine the $\mathrm{IC}_{50}$ values (Table 2). $(R, R)-\mathbf{1}$ shows superior cytotoxicity compared to cisplatin for both cancer cell lines while $(S, S)-\mathbf{1}$ has the lowest efficacy. The difference in activity 

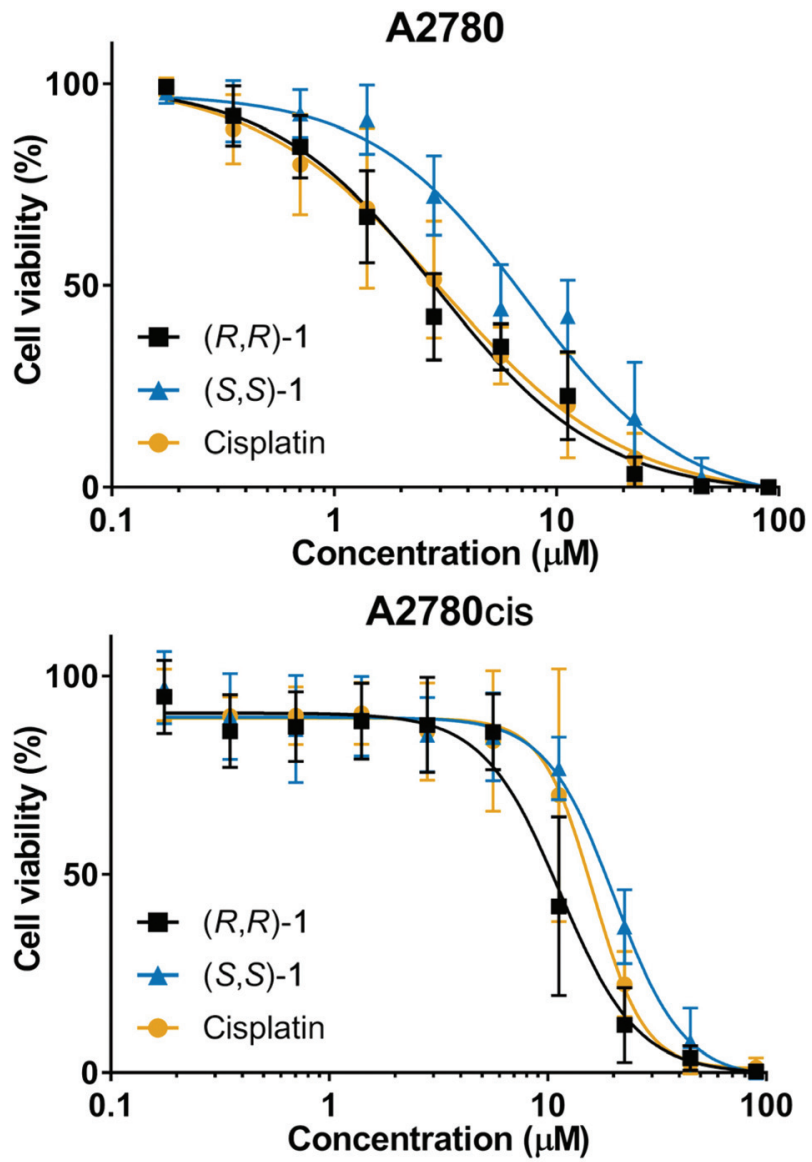

Fig. 6 Dose-response curves for $(R, R)-1,(S, S)-1$, and cisplatin on human ovarian cancer cell lines A2780 (top) and A2780cis (bottom).

Table 2 In vitro cytotoxicity of $(R, R)-1,(S, S)-1$, and cisplatin against human ovarian cancer lines $\mathrm{A} 2780$ and $\mathrm{A} 2780 \mathrm{cis}$

\begin{tabular}{llll}
\hline & $\mathrm{IC}_{50}(\mu \mathrm{M})^{a}$ & & \\
\cline { 2 - 4 } Cell line & $(S, S)-\mathbf{1}$ & $(R, R)-\mathbf{1}$ & Cisplatin \\
\hline A2780 & $6.85 \pm 1.21$ & $2.27 \pm 0.65$ & $3.28 \pm 0.63$ \\
A2780 cis $^{b}$ & $20.15 \pm 0.91$ & $11.2 \pm 0.66$ & $16.81 \pm 0.56$
\end{tabular}

${ }^{a} \mathrm{IC}_{50}$ values derived as mean $\pm \mathrm{SD}$ of results of eight parallel experiments done in triplicate for each platinum complex paired with each cell line and incubated for $72 \mathrm{~h}$ at $37{ }^{\circ} \mathrm{C} .{ }^{b}$ Cisplatin-resistant variant of A2780 cell line.

between the diaplatin stereoisomers is in line with previously observed pattern for oxaliplatin, which contains the $(R, R)$ DACH fragment. ${ }^{37,38}$ The difference in reactivity of oxaliplatin and its stereoisomer is attributed to a more favorable configuration of the resulting DNA cross-link. ${ }^{56-61}$ The cisplatin-resistant cell line A2780cis shows a notable decrease in response to platinum complexes in the same range of concentrations, although $(R, R)-\mathbf{1}$ retains its superior activity compared to cisplatin. The observed efficacy of simplest 1,2-diaminodiamantane platinum complexes can be further enhanced by substituting the chloride groups for other leaving ligands, which is a general approach to achieve enhanced solubility, and decreased overall toxicity for the human body. ${ }^{15,21,28,62-66}$

\section{Nucleotide binding experiments}

Formation of DNA cross-links is the crucial part of the platinum cytotoxicity mechanism. To study diaplatin complex $\mathbf{1}$ activity on nucleotides in comparison to cisplatin we chose guanosine monophosphate (GMP) and deoxyguanosine monophosphate (dGMP) as substrates (Fig. 7). The reaction between platinum complexes and GMP or dGMP causes substitution of their leaving ligands with corresponding nucleotide to form monoadducts that quickly lose a second leaving ligand forming bisadducts. The N7 atom of the purine fragment is known to be the preferred binding site<smiles>Nc1nc2c(ncn2[C@@H]2O[C@H](COP(=O)(O)O)[C@@H](O)[C@H]2O)c(=O)[nH]1</smiles>

Guanosine monophosphate (GMP)<smiles>Nc1nc2c(ncn2[C@H]2C[C@H](O)[C@@H](COP(=O)(O)O)O2)c(=O)[nH]1</smiles>
(dGMP)
Deoxyguanosine monophosphate

Fig. 7 Structures of used nucleotide substrates.
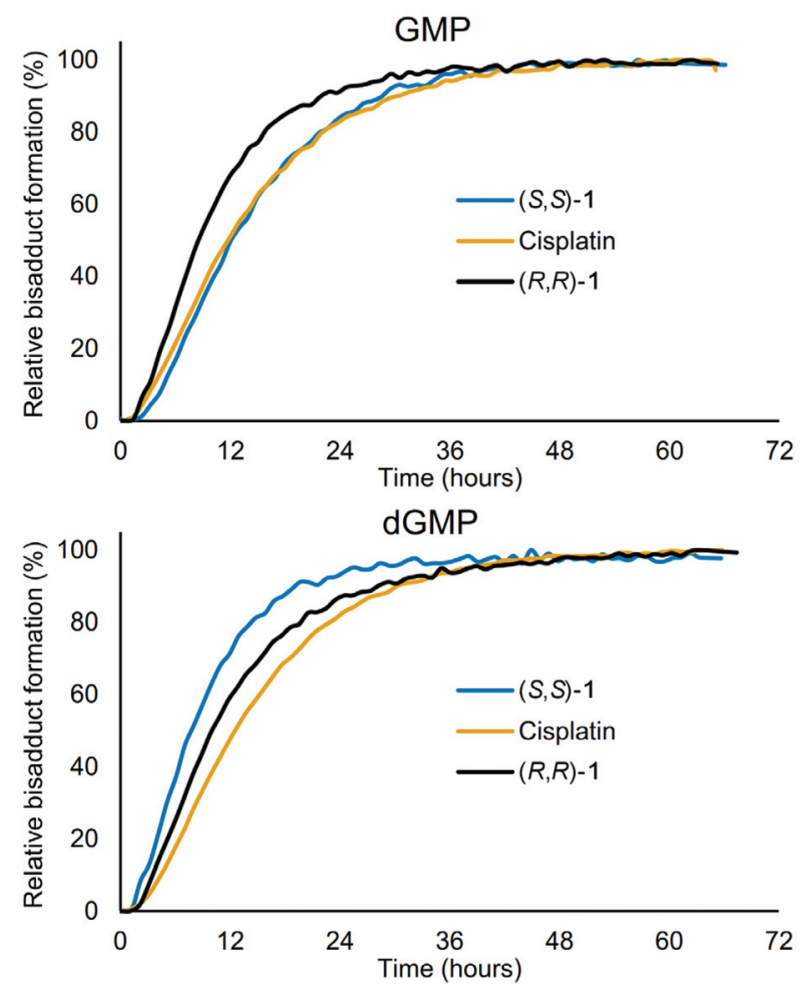

Fig. 8 Rates of nucleotide-platinum bisadduct formations for GMP (top) and dGMP (bottom). 
to platinum, ${ }^{67}$ thus causing easily observable downfield NMR shifts of the adjacent $\mathrm{H} 8$ atom. The collected ${ }^{1} \mathrm{H}$ NMR data during incubation of the reaction mixtures provide time-dependent changes of the $\mathrm{H} 8$ atom integral, thereby providing insights into the binding rates for the studied complexes (Fig. 8).

Both nucleotides form bisadducts faster with $(R, R)-\mathbf{1}$ than with cisplatin despite the bulky diamantane backbone. The $(S, S)$-1 bisadduct with GMP has a rate of formation close to cisplatin, but binding to deoxyguanosine proceeds faster than for $(R, R)-\mathbf{1}$ and cisplatin illustrating the impact of backbone chirality. Overall, diaplatin 1 showed noticeably faster reaction towards bisadduct formation despite greatly increased steric requirements posed by the diamantane moiety.

\section{Conclusions}

Here we put forward 1,2-diaminodiamantane as a viable nonleaving ligand for platinum-based anticancer drugs. We were able to prepare $(R, R)-\mathbf{1}$ and $(S, S)$-1 featuring chloride ligands despite decreased solubility compared to cisplatin. The analogous platinum complexes with oxalate moieties were found to have negligible solubility preventing them from being studied further. The crystallographic data allowed us to confirm the absolute configurations of the newly prepared complexes. The diamondoid moiety predictably changed the platinum complex towards significantly increased lipophilicity. A cytotoxic assay demonstrates the superiority of $(R, R)-\mathbf{1}$ relative to cisplatin on both the human ovarian cancer cell line A2780 and its cisplatin-resistant variant A2780cis. Complex $(S, S)-\mathbf{1}$ was found to be less potent than cisplatin on either cell line. This further demonstrated the difference in reactivity caused by the chiral diamine backbone interactions with DNA. Similar to oxaliplatin, which contains the $R, R$-enantiomer of trans-1,2diaminocyclohexane as the diamine ligand, $(R, R)$-1,2-diaminodiamantane yields the more potent cytotoxic complex. Nucleotide binding studies of the diaplatin enantiomers showed activities similar to other platinum(II) complexes. Despite the increased steric demand, both GMP and dGMP bind faster to $(R, R)-\mathbf{1}$ than to cisplatin. The $(S, S)-\mathbf{1}$ binding kinetics towards GMP are close to cisplatin, but in case of dGMP the rate is higher compared to $(R, R)-\mathbf{1}$ or cisplatin.

1,2-Diaminodiamantane provides an opportunity to utilize a pharmacophore with an unusual set of properties. At the cost of decreased solubility, the simplest platinum(II) complex based on this diamantane backbone already proved to be more potent than cisplatin on the studied cell lines while being as fast at binding with nucleotides as cisplatin despite considerably increased bulk. Furthermore, the straightforward diaplatin synthesis allows simple modifications of both the diamine and the leaving ligands as a way to improve solubility ${ }^{29}$ in addition to augmenting its pharmacokinetics.

\section{Conflicts of interest}

There are no conflicts to declare.

\section{Acknowledgements}

The work in Giessen was supported in part by the U.S. Department of Energy (Contract No. DE-AC0276SF00515). A. E. P. thanks Erasmus+Programme for support.

\section{Notes and references}

1 B. Rosenberg, Cancer, 1985, 55, 2303-2316.

2 N. J. Wheate, S. Walker, G. E. Craig and R. Oun, Dalton Trans., 2010, 39, 8113-8127.

3 L. Kelland, Nat. Rev. Cancer, 2007, 7, 573-584.

4 A. Eastman, Pharmacol. Ther., 1987, 34, 155-166.

5 S. Dasari and P. B. Tchounwou, Eur. J. Pharmacol., 2014, 740, 364-378.

6 I. Arany and R. L. Safirstein, Semin. Nephrol., 2003, 23, 460464.

7 S. Quasthoff and H. P. Hartung, J. Neurol., 2002, 249, 9-17.

8 A. A. Argyriou, J. Bruna, P. Marmiroli and G. Cavaletti, Crit. Rev. Oncol. Hematol., 2012, 82, 51-77.

9 X. L. Cheng, H. Q. Liu, Q. Wang, J. G. Huo, X. N. Wang and P. Cao, Front. Pharmacol., 2015, 6, 234.

10 S. B. Park, D. Goldstein, A. V. Krishnan, C. S. Lin, M. L. Friedlander, J. Cassidy, M. Koltzenburg and M. C. Kiernan, Ca-Cancer J. Clin., 2013, 63, 419-437.

11 M. J. McKeage, Drug Saf., 1995, 13, 228-244.

12 D. W. Shen, L. M. Pouliot, M. D. Hall and M. M. Gottesman, Pharmacol. Rev., 2012, 64, 706-721.

13 L. Galluzzi, L. Senovilla, I. Vitale, J. Michels, I. Martins, O. Kepp, M. Castedo and G. Kroemer, Oncogene, 2011, 31, 1869.

14 Z. H. Siddik, Oncogene, 2003, 22, 7265-7279.

15 S. Dilruba and G. V. Kalayda, Cancer Chemother. Pharmacol., 2016, 77, 1103-1124.

16 D. J. Stewart, Crit. Rev. Oncol. Hematol., 2007, 63, 12-31.

17 C. A. Rabik and M. E. Dolan, Cancer Treat. Rev., 2007, 33, 9-23.

18 O. Rixe, W. Ortuzar, M. Alvarez, R. Parker, E. Reed, K. Paull and T. Fojo, Biochem. Pharmacol., 1996, 52, 1855-1865.

19 J. Graham, M. Mushin and P. Kirkpatrick, Nat. Rev. Drug Discovery, 2004, 3, 11-12.

20 E. Raymond, S. G. Chaney, A. Taamma and E. Cvitkovic, Ann. Oncol., 1998, 9, 1053-1071.

21 Z. Jian, G. Shaohua and L. Fengfan, Chem. - Eur. J., 2014, 20, 15216-15225.

22 M. Fanelli, M. Formica, V. Fusi, L. Giorgi, M. Micheloni and P. Paoli, Coord. Chem. Rev., 2016, 310, 41-79.

23 J. Kasparkova, H. Kostrhunova, V. Novohradsky, J. Pracharova, A. Curci, N. Margiotta, G. Natile and V. Brabec, Dalton Trans., 2017, 46, 14139-14148. 
24 N. Margiotta, C. Marzano, V. Gandin, D. Osella, M. Ravera, E. Gabano, J. A. Platts, E. Petruzzella, J. D. Hoeschele and G. Natile, J. Med. Chem., 2012, 55, 7182-7192.

25 J. de Mier-Vinué, M. Gay, Á. M. Montaña, R.-I. Sáez, V. Moreno, J. Kasparkova, O. Vrana, P. Heringova, V. Brabec, A. Boccarelli, M. Coluccia and G. Natile, J. Med. Chem., 2008, 51, 424-431.

26 Á. M. Montaña, F. J. Bernal, J. Lorenzo, C. Farnós, C. Batalla, M. J. Prieto, V. Moreno, F. X. Avilés, J. M. Mesas and M.-T. Alegre, Bioorg. Med. Chem., 2008, 16, 17211737.

27 J. Lorenzo, A. Delgado, Á. M. Montaña, J. M. Mesas, M.-T. Alegre, M. d. C. Rodríguez and F.-X. Avilés, Eur. J. Med. Chem., 2014, 83, 374-388.

28 F. Liu, S. Gou, F. Chen, L. Fang and J. Zhao, J. Med. Chem., 2015, 58, 6368-6377.

29 F. Liu, W. Hu, L. Fang and S. Gou, J. Coord. Chem., 2016, 69, 1284-1292.

30 Z. Wang, M. Wu and S. Gou, J. Inorg. Biochem., 2016, 157, $1-7$.

31 A. E. G. E. Amr, K. A. Ali and M. M. Abdalla, Eur. J. Med. Chem., 2009, 44, 901-907.

32 L. Wanka, K. Iqbal and P. R. Schreiner, Chem. Rev., 2013, 113, 3516-3604.

33 T. P. Stockdale and C. M. Williams, Chem. Soc. Rev., 2015, 44, 7737-7763.

34 A. A. Fokin, A. E. Pashenko, V. V. Bakhonsky, T. S. Zhuk, L. V. Chernish, P. A. Gunchenko, A. O. Kushko, J. Becker, R. C. Wende and P. R. Schreiner, Synthesis, 2017, 49, 20032008.

35 F. Arnesano, A. Pannunzio, M. Coluccia and G. Natile, Coord. Chem. Rev., 2015, 284, 286-297.

36 Y. Kidani, K. Inagaki and S. Tsukagoshi, Gann, 1976, 67, 921-922.

37 Y. Kidani, K. Inagaki, M. Iigo, A. Hoshi and K. Kuretani, J. Med. Chem., 1978, 21, 1315-1318.

38 Y. Kidani, M. Noji and T. Tashiro, Gann, 1980, 71, 637-643.

39 L. Krause, R. Herbst-Irmer, G. M. Sheldrick and D. Stalke, J. Appl. Crystallogr., 2015, 48, 3-10.

40 G. M. Sheldrick, Acta Crystallogr., Sect. A: Found. Adv., 2015, 71, 3-8.

41 G. M. Sheldrick, Acta Crystallogr., Sect. C: Struct. Chem., 2015, 71, 3-8.

42 M. D. Hall, K. A. Telma, K.-E. Chang, T. D. Lee, J. P. Madigan, J. R. Lloyd, I. S. Goldlust, J. D. Hoeschele and M. M. Gottesman, Cancer Res., 2014, 74, 3913-3922.

43 S. Parsons, H. D. Flack and T. Wagner, Acta Crystallogr., Sect. B: Struct. Sci., Cryst. Eng. Mater., 2013, 69, 249-259.

44 B. Spingler, D. A. Whittington and S. J. Lippard, Inorg. Chem., 2001, 40, 5596-5602.
45 V. P. Ting, M. Schmidtmann, C. C. Wilson and M. T. Weller, Angew. Chem., Int. Ed., 2010, 49, 9408-9411.

46 C. Liang, J. Q. Qiao and H. Z. Lian, J. Chromatogr. A, 2017, 1528, 25-34.

47 D. Kempińska, T. Chmiel, A. Kot-Wasik, A. Mróz, Z. Mazerska and J. Namieśnik, TrAC, Trends Anal. Chem., 2019, 113, 54-73.

48 M. Sabbatini, I. Zanellato, M. Ravera, E. Gabano, E. Perin, B. Rangone and D. Osella, J. Med. Chem., 2019, 62, 33953406.

49 M. Klose, S. Theiner, H. Varbanov, D. Hoefer, V. Pichler, M. Galanski, S. Meier-Menches and B. Keppler, Inorganics, 2018, 6, 130.

50 J. Sangster, J. Phys. Chem. Ref. Data, 1989, 18, 1111-1229.

51 S. Pinsuwan, A. Li and S. H. Yalkowsky, J. Chem. Eng. Data, 1995, 40, 623-626.

52 J. P. Souchard, T. T. Ha, S. Cros and N. P. Johnson, J. Med. Chem., 1991, 34, 863-864.

53 L. Feng, A. De Dille, V. J. Jameson, L. Smith, W. S. Dernell and M. C. Manning, Cancer Chemother. Pharmacol., 2004, 54, 441-448.

54 A. F. Westendorf, L. Zerzankova, L. Salassa, P. J. Sadler, V. Brabec and P. J. Bednarski, J. Inorg. Biochem., 2011, 105, 652-662.

55 J. J. Wilson and S. J. Lippard, J. Med. Chem., 2012, 55, 5326-5336.

56 J. Yang, J. Chen and Z. Li, Aust. J. Chem., 2016, 69, 379-387. 57 H. Y. Zhang, Y. R. Liu, C. Ji, W. Li, S. X. Dou, P. Xie, W. C. Wang, L. Y. Zhang and P. Y. Wang, PLoS One, 2013, 8, e71556.

58 K. Jana, V. Marie, N. Giovanni and B. Viktor, Chem. - Eur. J., 2008, 14, 1330-1341.

59 J. Malina, O. Novakova, M. Vojtiskova, G. Natile and V. Brabec, Biophys. J., 2007, 93, 3950-3962.

60 F. P. Fanizzi, F. P. Intini, L. Maresca, G. Natile and R. Quaranta, Inorg. Chim. Acta, 1987, 137, 45-51.

61 M. Noji, K. Okamoto, Y. Kidani and T. Tashiro, J. Med. Chem., 1981, 24, 508-515.

62 A. M. Montana and C. Batalla, Curr. Med. Chem., 2009, 16, 2235-2260.

63 B. J. Pages, D. L. Ang, E. P. Wright and J. R. Aldrich-Wright, Dalton Trans., 2015, 44, 3505-3526.

64 J. Zhao, S. Gou and F. Liu, Chem. - Eur. J., 2014, 20, 1521615225.

65 J. J. Wilson and S. J. Lippard, Chem. Rev., 2014, 114, 44704495.

66 I. Ali, W. A. Wani, K. Saleem and A. Haque, Anti-Cancer Agents Med. Chem., 2013, 13, 296-306.

67 G. Y. H. Chu, S. Mansy, R. E. Duncan and R. S. Tobias, J. Am. Chem. Soc., 1978, 100, 593-606. 